\title{
Simulation and experimental study on the Self-excited oscillation jet device
}

\author{
Yong Chen ${ }^{1,}$ a , Chen Chen ${ }^{2, b}$ \\ 1,2 College of Construction Engineering, Jilin University, Chang Chun, 130061, China \\ a496489653@qq.com, bchenchen@jlu.edu.com
}

\begin{abstract}
Keywords: The self-excited oscillation pulsed jet, numerical simulation, crush experiment.
Abstract. Nearly 40 years, high pressure water jet technology has developed rapidly and increasingly[1,2], and it also added new methods to foundation engineering and geotechnical engineering for our country[3,4,5], such as High pressure jet grouting[6] and coal or ore mining[7,8], so choose what kind of jet can be more effective to crush rock became the focus of researching $[9,10]$. In this paper, using the Fluent software numerical simulation technology to research the inlet velocity of jet from $5 \mathrm{~m} / \mathrm{s}$ to $300 \mathrm{~m} / \mathrm{s}$ and hit a target from $100 \mathrm{~mm}$ to $800 \mathrm{~mm}$, exploring the hit force variation rule of oscillation pulsed jet. Then according to the variation curve draw force formula. Put forward that in the low velocity using exponential function fitting, and high velocity using the polynomial function fitting. Then tested self-excited oscillation pulsed jet force, the results is similar to the numerical simulation. And finally do contrast experiment between self-excited oscillation pulsed jet and consecutive jets, found that at low pressure condition, self-excited oscillation pulsed jet can crushing rock easier.
\end{abstract}

\section{Introduction}

\section{The research background and significance}

Nearly 40 years, high pressure water jet technology has developed rapidly and increasingly[1,2], and it has become a perfect new tool to clean, cut and crush. High pressure water jet technology also added new methods to foundation engineering and geotechnical engineering for our country[3,4,5,], such as High pressure jet grouting[6] and coal or ore mining[7,8] ,so choose what kind of jet can be more efficient and broken rock become the focus of researching $[9,10]$. This paper mainly for exploring the self-excited oscillation pulsed jet device hitting force and it's capacity of crushing rock. The main research contents and technical route The main research content of this paper is:

(1) Numerical simulation based on Fluent, establish Self-excited oscillation nozzle internal and external flow field model, and make simulation of different jet distance and entrance velocity. Finally, analyze the data to explore the change rule of the force of the self-excited oscillation pulsed jet.

(2) By using the existing test bench to do force experiment and compared with the results of simulation; Doing crush experiment to standard sample in submerged and non-submerged condition and evaluate the experiment results

Technical route of this paper is shown in Fig. 1. 


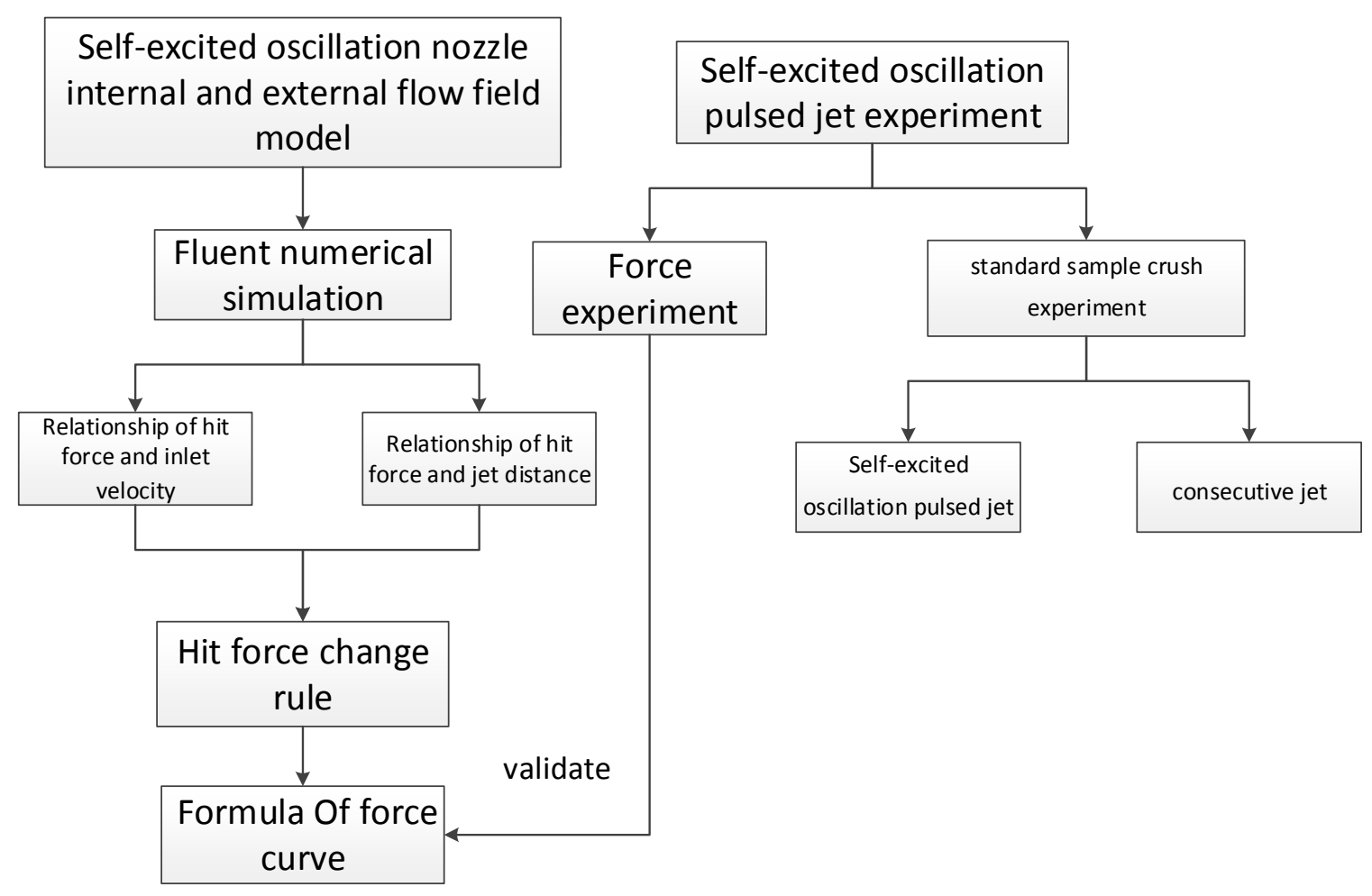

Fig.1 technical route

\section{Numerical simulation}

According to the test bench and the size of the self-excited oscillation jet parameters draw different jet distance flow field model, and meshing the model, then importing the model to Fluent software to do simulation of entrance velocity from $5 \mathrm{~m} / \mathrm{s}$ to $300 \mathrm{~m} / \mathrm{s}$. After post-processing can have pressure, speed of cloud image and target plate force reports. Part of the results of numerical simulation is shown in Fig 2.1.
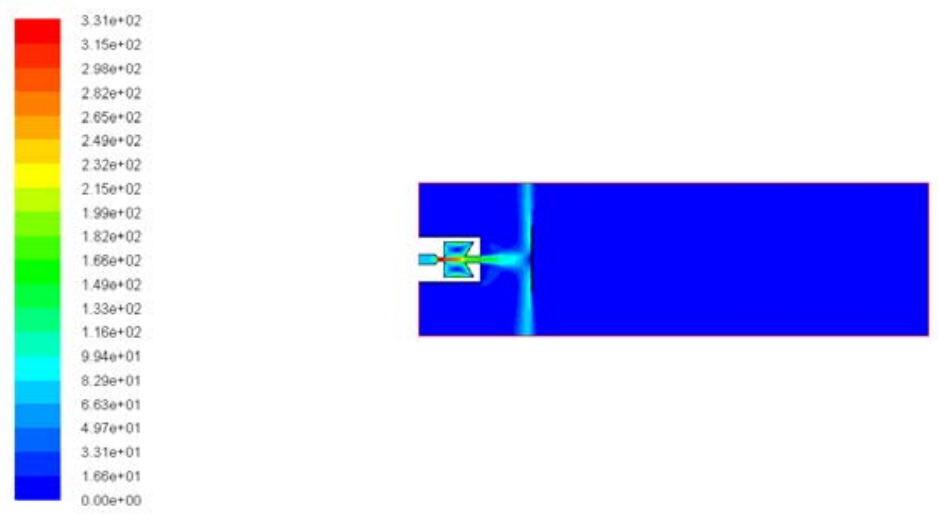

(a)Jet distance $100 \mathrm{~mm}$, inlet velocity of $80 \mathrm{~m} / \mathrm{s}$ velocity contour
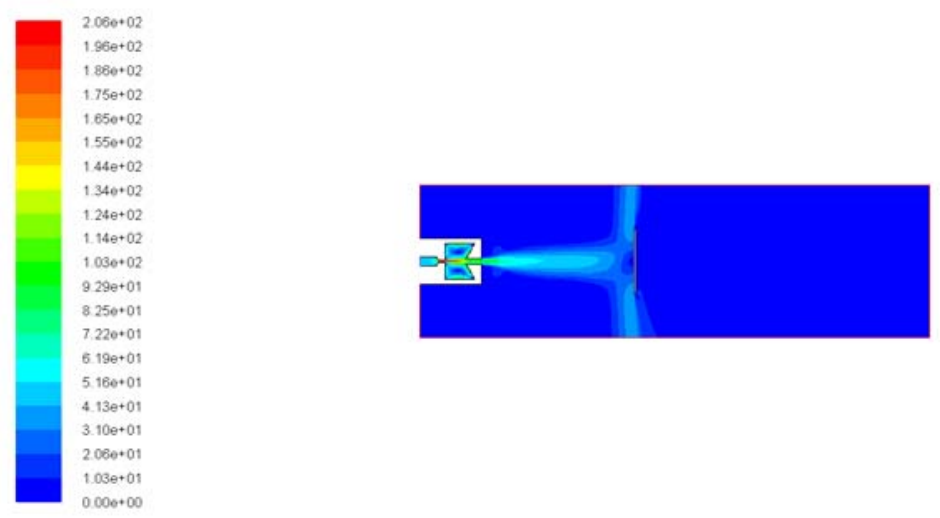
(b) Jet distance $300 \mathrm{~mm}$, inlet velocity of $80 \mathrm{~m} / \mathrm{s}$ velocity contour
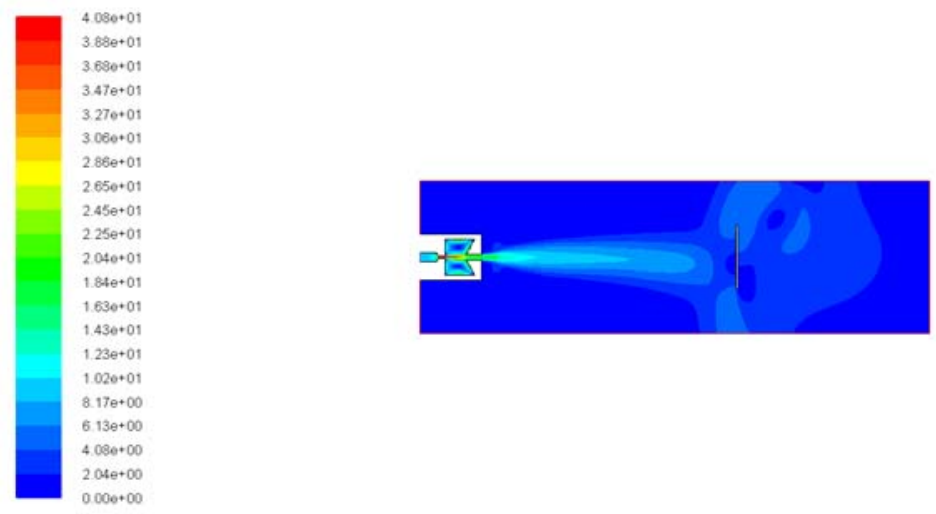

(c) Jet distance $500 \mathrm{~mm}$, inlet velocity of $10 \mathrm{~m} / \mathrm{s}$ velocity contour

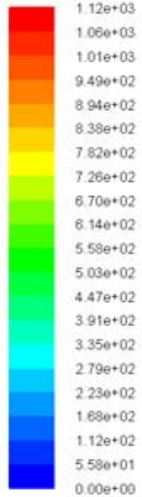

(d)Jet distance $800 \mathrm{~mm}$, inlet velocity of $300 \mathrm{~m} / \mathrm{s}$ velocity contour

Fig 2.1 part of the results of numerical simulation

\section{Analysis of the force Based on the numerical simulation}

The target plate force variation curve of $100 \mathrm{~mm}, 300 \mathrm{~mm}, 500 \mathrm{~mm}$ and $800 \mathrm{~mm}$ jet distance is shown in Fig 2.2.

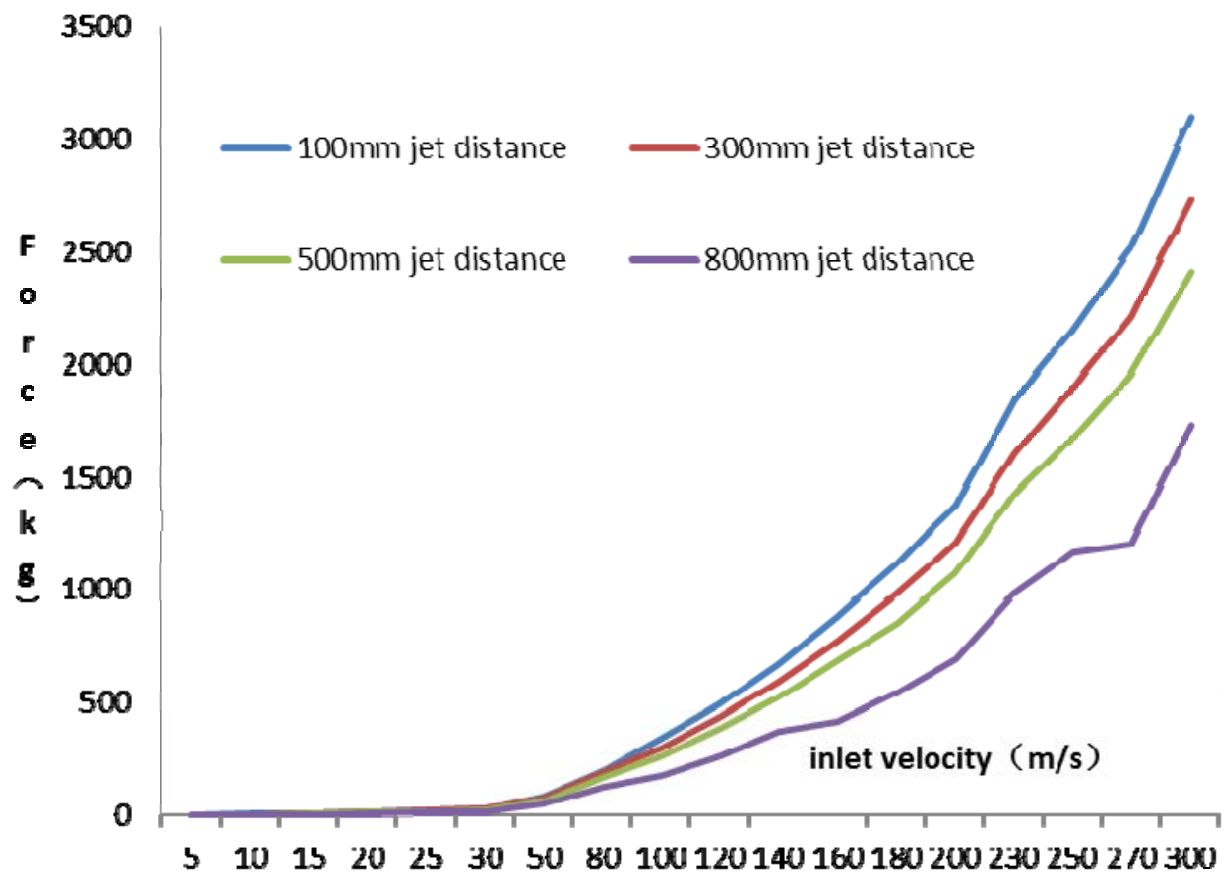

Fig 2.2Curve of hitting force 
Make function fitting to the curve of 100mm jet distance, shown in Fig 2.3.

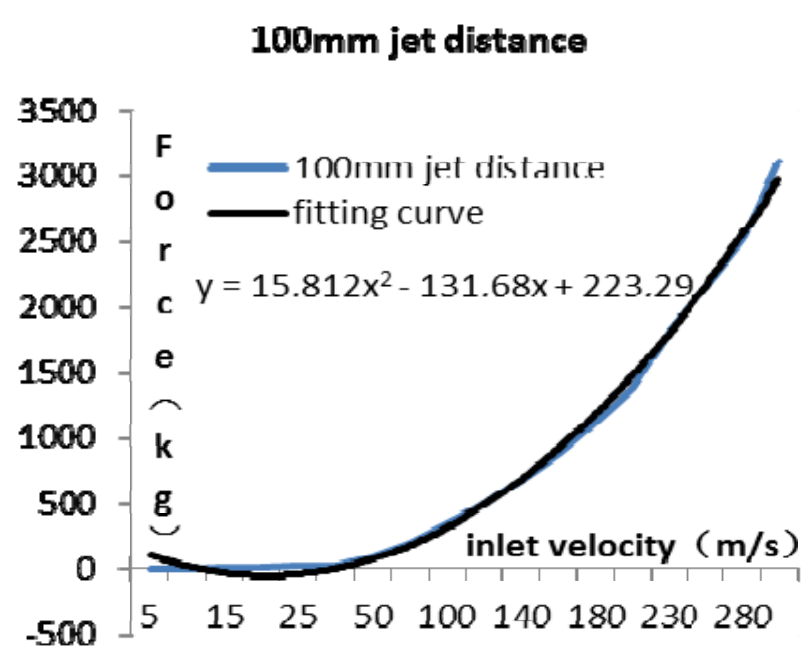

$100 \mathrm{~mm}$ jet distance

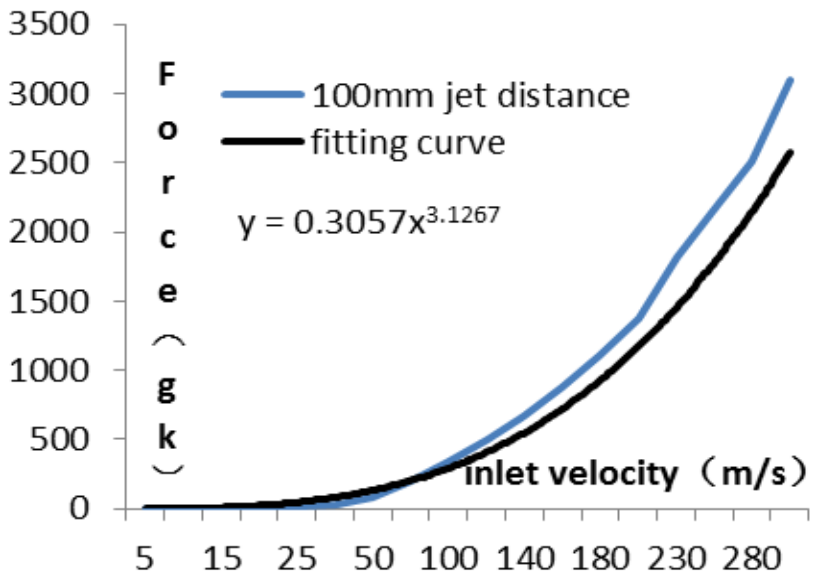

Fig 2.3 fitting curve

The fitting result shows that the power function is suitable for the low inlet velocity condition, while polynomial is more suitable for high inlet velocity condition. So $100 \mathrm{~mm}$ force formula should be described by the piecewise function Eq1 :

$$
F=\left\{\begin{array}{c}
0,3057 v^{5125}, v \leq 30 \\
13,812 v^{2}-131,08 v+223,3, v>30
\end{array}\right.
$$

Here $\mathrm{F}$ is target plate force $(\mathrm{kg}), v$ is entrance velocity.

According to table 2.1 curve of different jet distance have the same change trend, all can be expressed as Eq 2:

$$
\mathrm{I}=\left\{\begin{array}{c}
A v^{2}, v \leq 30 \\
C v^{2}-D v+E, v \geqslant 30
\end{array}\right.
$$

Here A, B, C, D and E are related to the target distance, the nozzle structure parameters.

\section{The self-excited oscillation pulsed jet force test}

In this paper, tested jet force of $100 \mathrm{~mm}, 300 \mathrm{~mm}, 500 \mathrm{~mm}$ and $800 \mathrm{~mm}$ jet distance respectively, compared with the results of numerical simulation, different target distance force test results compared with numerical simulation is shown in Table 3.1. It can be seen that the trends are the same, can think they are approximate matches.

Table 3.1 Force contrast

(a) $100 \mathrm{~mm}$

\begin{tabular}{|c|c|c|}
\hline Inlet velocity(m/s) & Fluent results $(\mathrm{kg})$ & Experiment results(kg) \\
\hline 5 & 0.79 & 0.42 \\
\hline 10 & 3.35 & 2.2 \\
\hline 15 & 7.2 & 4.5 \\
\hline
\end{tabular}

(b) $300 \mathrm{~mm}$

\begin{tabular}{|c|c|c|}
\hline Inlet velocity $(\mathrm{m} / \mathrm{s})$ & Fluent results $(\mathrm{kg})$ & Experiment results(kg) \\
\hline 5 & 0.69 & 0.4 \\
\hline 10 & 2.9 & 2.1 \\
\hline 15 & 6.7 & 4.3 \\
\hline
\end{tabular}

(c) $500 \mathrm{~mm}$ 


\begin{tabular}{|c|c|c|}
\hline Inlet velocity $(\mathrm{m} / \mathrm{s})$ & Fluent results $(\mathrm{kg})$ & Experiment results(kg) \\
\hline 5 & 0.6 & 0.36 \\
\hline 10 & 2.16 & 2.04 \\
\hline 15 & 5.7 & 4.2 \\
\hline
\end{tabular}

(d) $800 \mathrm{~mm}$

\begin{tabular}{|c|c|c|}
\hline Inlet velocity $(\mathrm{m} / \mathrm{s})$ & fluent results $(\mathrm{kg})$ & experiment results $(\mathrm{kg})$ \\
\hline 5 & 0.50 & 0.22 \\
\hline 10 & 2.36 & 2.02 \\
\hline 15 & 4.3 & 3.96 \\
\hline
\end{tabular}

\section{Self-excited oscillation pulsed jet standard sample crush experiment}

Firstly, doing self-excited oscillation pulse jet experiment. After fixed the sample, do the experiment in the condition of target distance $100 \mathrm{~mm}, 2.2 \mathrm{MPa}$ pressure for 2 minutes. Fig 3.4 is the sample picture of before and after the experiment.

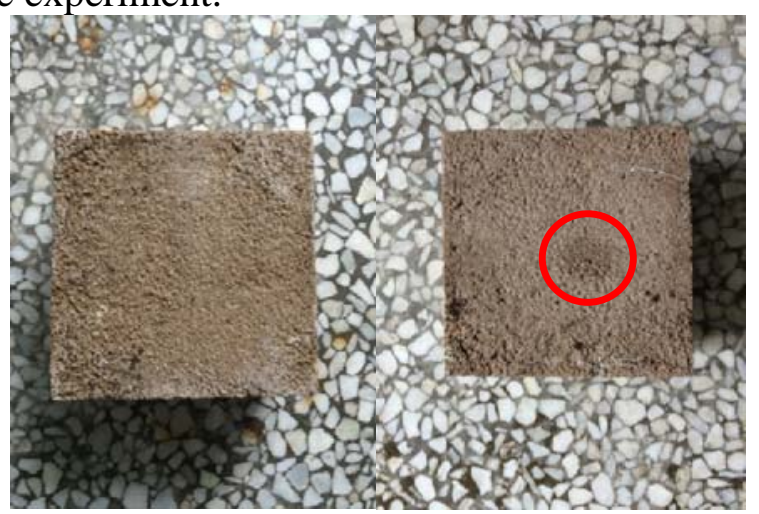

Fig 3.2 self-excited oscillation pulse jet crush experiment

After experiment, the place of red round appeared a diameter of about $3 \mathrm{~cm}$, deep $1.5 \mathrm{~mm}$ shallow pits.

Then, doing consecutive jets experiment. After fixed the sample, do the experiment in the condition of target distance $100 \mathrm{~mm}, 2.2 \mathrm{MPa}$ pressure for 2 minutes. After experiment found that sample has no change. Fig 3.3 is the sample picture of before and after the experiment.

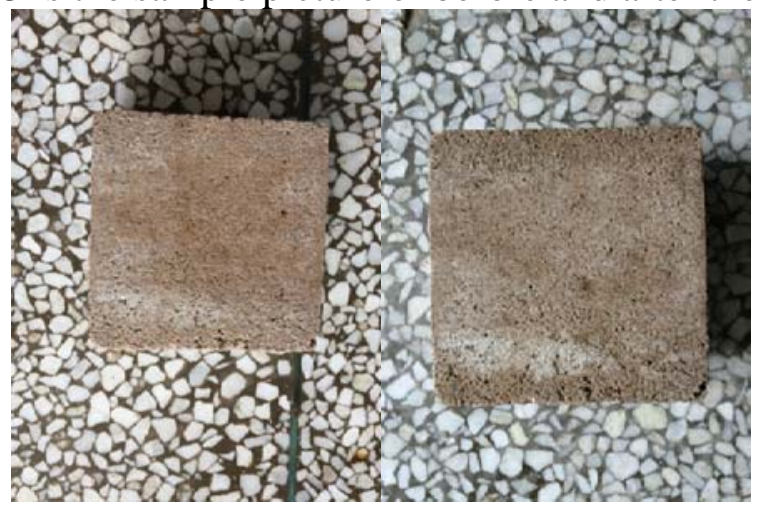

Fig 3.3 consecutive jets crush experiment

\section{Conclusions}

(1) By using Fluent software, through changing the inlet velocity and hit the target distance get force change rule: the force difference is not big in low inlet velocity, while, the force difference is more and more big after inlet velocity more than $30 \mathrm{~m} / \mathrm{s}$;

(2) Force change curves at high velocity are closer to the polynomial function, and closer to the exponential function in low velocity;

(3) At low pressure condition, self-excited oscillation pulsed jet can crushing rock easier compared with continuous jet. 


\section{Acknowledgements}

This work was financially supported by the Drilling hydraulic mining lab of College of Construction Engineering of Jilin University. And thanks a lot to my tutor, Chen Chen professor.

\section{References}

[1] Zhonghou Shen. Water jet theory and technology[M].Dong Ying: China petroleum university press, 1998. In Chinese

[2] Shengxiong Xue. High pressure water jet technology engineering [M]. HeFei: Hefei university of technology press, 2006. In Chinese

[3] Jiajun Sun. Water jet cutting technology [M]. Xu Zhou: China mining university press, 1992. In Chinese

[4] RuiheWang. Mechanism of high pressure water jet is studied [M]. China petroleum university press, 2010. In Chinese

[5] Chen Chen. :The geological, 1998, 17(10): 85-87. In Chinese

[6]. Chen Chen. Geotechnical Eneineering Construction[M] BeiJing: Geological publishing house, 2015. In Chinese

[7] Chen Chen. Youhong Sun:Prospecting engineering: Rock and soil drilling and digging engineering, 2010, 37(10): 26-29. In Chinese

[8] Qian Li. High pressure water jet drilling deep hole in the experimental study on the soft coal seam[D]. Chong Qing: ChongQing University, 2008. In Chinese

[9] Jiwei Wen. Numerical Simulation and Experimental Research on the Jet Devices for Hydraulic Borehole Mining of Oil Shale [D]. ChangChun: Jilin University, 2014. In Chinese

[10] Xunming Wang, Influence Factors Numerical Simulation Study of the Self-exited Oscillation Pulsed Jet Device and Nozzle Structure Optimized Design[D]. HangZhou: Zhejiang University, 2005. In Chinese 